\title{
Do mind and body agree? Unconscious versus conscious arousal in product attitude formation
}

\author{
Debora Bettiga $^{1 \mathrm{a}}$, Lucio Lamberti ${ }^{1 \mathrm{f}}$, Giuliano Noci ${ }^{\mathrm{h}}$ \\ ${ }^{1}$ Department of Management, Economics and Industrial Engineering - Politecnico di Milano \\ Via Lambruschini 4B - 20156 Milan (Italy) \\ a Corresponding author: debora.bettiga@ polimi.it, phone: +39 0223992816 \\ flucio.lamberti@polimi.it, h giuliano.noci@polimi.it
}

\begin{abstract}
Marketing research addressing the role of arousal in attitude formation and change mostly looks at arousal as a merely conscious emotion. However, a substantial body of research, in cognitive psychology and neuroscience, now offers insights on the implicit, subliminal reactions of individuals to external stimuli, sustaining that unconscious emotions may drive to different attitudinal responses. Following a conceptualization of conscious and unconscious arousal and its influence on product attitude formation, this study provides empirical evidence of the hypothesised relationships through a laboratory experiment on 160 subjects. By employing electrodermal activity, a physiological measure, to assess unconscious arousal and self-reported scales to assess conscious arousal, the study reveals that conscious and unconscious arousal are two independent emotional responses and they influence attitude toward the product differently. The study extends theory on emotions and provides an initial step toward using physiological measures to evaluate consumer emotional response to new products.
\end{abstract}

Keywords: unconscious arousal; attitude; emotion; product trial; electrodermal activity;

\section{Introduction}

Arousal constitutes a strong, predictable and impactful driver of decision making with regularities in the mechanisms through which it influences product evaluation across different types of decisions (Lerner, Li, Valdesolo, \& Kassam, 2015). The understanding of the processes through which arousal influences attitude toward products and consequently, purchase intention, is significant for companies. Managers, indeed, need to understand how to design their products and communication to deliver a remarkable consumer experience that generates 
purchase intention. Knowing the mental process leading to attitude formation may enable managers to get their audience's attention and stimulate interest toward the offer.

Despite a substantial literature has emerged on the role of arousal in attitude formation and change (e.g. Allen, Machleit, Kleine, \& Notani, 2005; Bagozzi, Gopinath, \& Nyer, 1999), it mostly looked at arousal as a merely subjective felt emotion, i.e. an emotional response consciously experienced and generated by the identification of the eliciting cause (Kihlstrom, 1990). However, research acknowledged that most emotions that determine thought and behaviour occur without awareness (Zaltman, 1997). Studies in cognitive psychology, analysing individuals' psychological consciousness and unconsciousness (Berridge \& Winkielman, 2003; Kihlstrom, Mulvaney, Tobias, \& Tobis, 2000; Kihlstrom, 1990, 1992), established that, above emotions that are consciously experienced, individuals may experience unconscious emotions too. More recently, research in cognitive neurosciences (Dehaene, Changeux, \& Naccache, 2011; Lane, Nadel, Allen, \& Kaszniak, 2000; Smith \& Lane, 2016), focusing on the distinction between implicit and explicit processes of cognition, has come to a similar conclusion, acknowledging that the implicit-explicit distinction that applies to cognition generally also applies to emotions. Such unconscious emotions, i.e. emotional responses either consciously experienced but without identification of the eliciting cause or generated but not consciously recognised (Kihlstrom et al., 2000), can drive to different behavioural responses (Gardner, 1985; Hill \& Gardner, 1987). These studies are grounded on the seminal concept that if arousal is the perception of bodily activity and perceptions can be unconscious, arousal can be unconscious too and may be expressed without awareness via physiological responses (James, 1884). This means that arousal is essentially a bodily reaction, thus unconscious, and the emotions one feels are only the cognitive recognition of this bodily reaction (Schachter \& Singer, 1962). If research has not provided clear evidence of the divergence of unconscious and conscious arousal, researchers have at least accepted that without physiological activity consideration, emotions would be hardly distinguished from non-emotions (Lazarus, 1991). Consequently, the autonomic nervous system together with other unconscious physiological processes should come along with subjectively felt emotions (Oatley, 1992).

Despite the acknowledged role of physiological, unconscious arousal in shaping consumers' evaluations and behaviours, most of the research on this issue has been conducted in psychology and neuroscience and has not been widely acknowledged in marketing yet (Lee, Broderick, \& Chamberlain, 2007). Much remains to be done in marketing research before we can make definitive statements about the nature and role of arousal in individuals experience and 
cognitive evaluations. Hence, the aim of this study is to expand the examination of arousal, by analysing both its conscious and unconscious components, and its role in product attitude formation. Our hypothesis is that conscious arousal and unconscious arousal are two distinct emotional responses, the first representing a consciously accessible emotion, the second mirroring an unrecognised bodily activation. We propose that arousal, above influencing attitude through its conscious manifestation, is also involved in purely unconscious processing. Further, we propose that emotional and attitudinal responses may be processed differently according to the functional or hedonic nature of the product experienced and the context in which the experience occurs.

We extend existing research with four main contributions: (i) we broaden prior literature on arousal by providing a conceptual model on the relation between unconscious and conscious arousal and their influence on attitude (ii) we empirically measure arousal through both selfreported scales and physiological instruments, to assess the two components we hypothesize (iii) we provide empirical evidence of the influence of conscious and unconscious arousal on product attitude formation (iv) we advance research on the influence of product nature and trial context on product attitude formation. For the best of our knowledge, this is the first attempt to analyse the relationship between conscious and unconscious arousal and their influence on attitude in a marketing study.

\section{Literature background and hypotheses development}

In developing our conceptual framework (Figure 1), we rooted on a broad set of domains including psychology, neuro and biosciences, in order to conceptualise conscious and unconscious arousal and its influence on product attitude formation. Our framework proposes that, when a consumer experiences a product, both dimensions of arousal influence attitude formation and they are conceptually and practically independent. Further, we proffer that such relationships may be impacted by the nature of the product experienced and by the characteristics of the context in which the experience occurs. In the following, the conceptual framework is detailed in order to ground the research hypotheses tested in the study. Specifically, we begin with a definition and discussion of conscious and unconscious arousal, then turn on the influence of arousal on attitude. Finally, we consider the role of product nature and trial context.

[Figure 1 about here] 
2.1 Arousal: conscious and unconscious responses

From a physiological perspective, arousal is a fundamental component of behaviour (GroeppelKlein, 2005). Arousal conveys excitement, stimulation and bodily activation. It indicates an active body reaction, thus is closely related to attention to relevant outside stimuli and their processing. It affects decision-making processes and behaviours, such as the time spent browsing a product web page or the time spent in store (Groeppel-Klein, 2005). Arousal can have a positive or a negative valence: for instance, a subject can be positively excited by a new product or show negative arousal toward a product complex to use (Baker, Levy, \& Grewal, 1992; Ward \& Barnes, 2001).

Despite the overwhelming majority of research conducted in marketing refers to arousal as a conscious feeling, there is a growing stream of research in psychology, neuro and biosciences focusing on the unconscious side of arousal, arising thanks to the advancement in the measurement of physiological reactions. Studies in cognitive psychology, focusing on the understanding of individual consciousness (Berridge \& Winkielman, 2003; Kihlstrom et al., 2000; Kihlstrom, 1990, 1992), established that, above emotions that are consciously experienced, individuals may experience implicit emotions as well. While the topic has generated interest in psychiatry and clinical psychology (Brenner, 1973; Modell, 2010), analysing the potential explanatory role of unconscious emotions in psychopathology, it has recently gathered attention within cognitive neuroscience as well. Here research (Lane, Nadel, Allen, \& Kaszniak, 2000; Smith \& Lane, 2016; Dehaene, Changeux, \& Naccache, 2011) analyzing conscious versus unconscious processes occurring in perception, decision-making and cognitive control, comes to the conclusion that the implicit-explicit distinction that applies to cognition generally applies to emotions as well. Further, recent cognitive neuroscience studies outline neuro-cognitive mechanisms that explain why certain aspects of individual's emotional reactions might remain unconscious under specific circumstances (Smith \& Lane, 2016). This body of research supports the seminal theory of James (1884), confirmed by Schachter \& Singer (1962), assuming that if arousal is the perception of bodily activity and perceptions can be unconscious, arousal can be unconscious as well and may be expressed without awareness via physiological responses (James, 1884). According to these theories, different stimuli elicit different bodily responses (e.g. increasing heart rate), subsequently detected by the mind as bodily sensations and finally interpreted as emotional experiences.

Several researchers have confirmed that perceptions can be of an unconscious nature (Berridge \& Winkielman, 2003; Kihlstrom, 1992) and that some adults may lack emotional awareness at 
all or have low levels of it (Lane, Quinlan, Schwartz, Walker, \& Zeitlin, 1990). Kihlstrom et al. (2000) and more recently Smith and Lane (2016) have provided a clear guidance on the nature of conscious and unconscious emotions. They argue that the first involve situations in which emotional responses are consciously experienced and they are generated by the identification of the eliciting cause, also called explicit emotions (Kihlstrom, 1990). For instance, a consumer might consciously perceive a product and consciously experience excitement because of its amazing design. In contrast to such cases, what is labelled "unconscious emotion" (Kihlstrom et al., 2000) refers to an emotional response either consciously experienced but without identification of the eliciting cause or generated but not consciously recognised. The first could be the case of an individual that consciously perceives the product and consciously experiences excitement but is not aware that the product design causes the feeling. The second could be the case of a consumer showing a high bodily activation, such as increasing sweating or breath rate while interacting with a product but not reporting conscious feelings. Thus, when an emotional reaction is generated it may or may not become consciously accessible, i.e. individuals may not be aware of their unconscious bodily response. Conversely, a consumer may become aware of a bodily reaction, but fail to consciously recognise this reaction as an emotion (Smith \& Lane, 2016). Similarly, the Global Neuronal Workspace (GNW) model (Dehaene et al., 2011; Sergent \& Dehaene, 2004; Smith \& Lane, 2016) suggests that unconscious perceptual processes operate in parallel: most of the information that is represented unconsciously fails to enter consciousness, thus is not reportable by individuals. Conscious and unconscious feelings can become desynchronized from one another (Hodgson \& Rachman, 1974; Rachman \& Hodgson, 1974).

Despite the theoretical conceptualization of conscious and unconscious arousal and its relevance in product and service evaluation, extant research in marketing does not provide empirical evidence of such dimensions. Empirical investigation is limited to very few studies in psychophysiology and neuroscience that did not converge to a conclusive evidence. Drachen \& Nacke (2010) in a study of player experience assessed conscious arousal (subjectively measured) and unconscious one (physiologically measured). They found unconscious arousal positively correlated with conscious negative affect, but did not find any significant correlation with other self-reported measures of experience, such as tension or flow. Conversely, Gavazzeni, Wiens, \& Fischer (2008) found a significant correlation, ranging from 0.19 to 0.41 between conscious and unconscious arousal. Similarly, Groeppel-Klein (2005) showed a positive correlation between unconscious arousal and the emotion of joy, reported by subjects. 
Despite these studies, meta-analytic summaries fail to find a pattern between unconscious responses and conscious emotions (Cacioppo \& Berntson, 2000). Grounding on the research presented before, we hypothesise that conscious arousal and unconscious arousal are two distinct emotional responses, the first representing a consciously accessible emotion, the second mirroring an unrecognised bodily activation. Thus, more formally:

H1: There is no relationship between unconscious arousal and conscious arousal elicited by a product

\subsection{The relationship between attitude and arousal}

Attitude refers to an individual's enduring favourable or unfavourable evaluation of an object (Fishbein \& Ajzen, 1975) that arises from beliefs, feelings, and behavioural inclinations towards the product and its meaning (Vaughan \& Hogg, 2005). The utility of the attitude concept rests on the assumption that attitude influences behaviours, as Fishbein \& Ajzen (1975) famously argued. Attitude, indeed, influences purchasing behaviours through both direct processes, by unmediated influence on behaviours, and indirect processes, by influencing intention, in its turn inducing behaviours (Bentler and Speckart 1979).

Arousal plays a significant role in the formation of attitudes for different contexts and products (Bagozzi, 1996; Kim \& Morris, 2007; Sanbonmatsu \& Kardes, 1988). It is concurrently required in the generation of either positive or negative affect, thus both positive and negative emotional reactions (Mano \& Oliver, 1993). However, there is still controversy on how arousal impacts the cognitive process itself, thus the degree of elaboration used during exposure to a stimulus. What is acknowledged is that it may affect attitude via both changes in the content of thought and in depth of thought (Isen, Daubman, \& Nowicki, 1987; Lerner et al., 2015). Arousal directly influences the evaluation of a product by affecting the dimensions the consumer focuses on, and if he uses heuristics or analytic processing in evaluation (Lerner et al., 2015). Research argues that positive emotional reactions generated by a stimulus are transferred to the product and augment accessibility of favourable evaluations, leading to more positive product judgments (Isen et al., 1987). Thus, if consumers see a product as exciting and generating positive arousal, this may favourably affect their attitude. Conversely, negative arousal attributed to a product, such as disgust, may negatively affect attitude.

While these processes seem mostly based on an evaluation process by the individual, that influences product judgements, arousal seems also involved in purely unconscious processing. Higher arousal, indeed, has been proven to reduce the processing capacity available for 
cognitive processes; in such a circumstance, peripheral cues, such as unconscious arousal itself may have a stronger impact on attitude favorability (Sanbonmatsu \& Kardes, 1988). Unconscious arousal may reflect various types of psychological processes, with positive or negative valence (Bauer, 1998). Psychophysiological research established that subliminal presentations of negative emotional stimuli, which are not accessible to individuals' conscious awareness, generate unconscious arousal in subjects (Kimura, Yoshino, Takahashi, \& Nomura, 2004; Sato \& Aoki, 2006; Zaidel, Hugdahl, \& Johnsen, 1995). Such emotional reactions are activated automatically and processed subconsciously (Bagozzi et al., 1999) and are able to influence human cognition (Ivonin, Chang, Chen, \& Rauterberg, 2013).

Therefore, both conscious arousal and unconscious arousal may be able to influence attitude, with either positive or negative valence. Extending this argument, there should be instances in which the effect on attitude of the two responses (conscious arousal and unconscious arousal) is disassociated: individuals, indeed, may not be able to recognize unconscious arousal reactions, either because they link the arousal state to an incorrect cause or because they assign it an incorrect label, meaning that unconscious emotional processes distinguish from the cognitive processes involved in cause attribution and labeling (Winkielman \& Berridge, 2005). Further, this disassociation may be intensified if individuals feel a strong, high arousal, as this could result in a decreased ability to recognise the conceptual emotional meaning of the individual current state (Smith \& Lane, 2016). Conversely, even if unconscious reactions are not elicited, meaning that the individual does not show bodily responses - e.g. no changes in heart rate -, individuals might unconsciously represent the bodily reaction as if it were in place - e.g. increase in heart rate - (Wiens, 2005). Therefore, in both scenario, conscious arousal and unconscious arousal are generated through different processes and their manifestation may be different. Consequently, we assume that even if both conscious arousal and unconscious arousal influence attitude, the valence of such responses may be dissociated. We formalise our hypotheses below:

H2: Conscious arousal elicited by a product influences attitude toward the product, with either positive or negative valence

H3: Unconscious arousal elicited by a product influences attitude toward the product, with either positive or negative valence 
2.3 The role of product nature and trial context

Extant research (Batra \& Ahtola, 1991; Kempf \& Smith, 1998; Kempf, 1999) argues that consumer emotional and attitudinal responses may be processed differently by individuals according to the mainly hedonic or functional nature of the product they are evaluating. Hedonic products are the ones that embed a more experiential consumption, providing fun, pleasure, excitement and delight while functional (utilitarian) products are primarily satisfying practical and functional needs (Hirschman \& Holbrook, 1982; Strahilevitz \& Myers, 1998; Wertenbroch \& Dhar, 2000). Hedonic products have been acknowledged as sources of fantasies and emotional arousal (Hirschman \& Holbrook, 1982) excitement and delight (Chitturi, Raghunathan, \& Mahajan, 2008). These emotional responses have been argued to strongly influence consumers' evaluations and attitude, being hedonic products judged primarily on affective dimensions (Kempf, 1999). Arousal, in particular, seems to be related to emotional evaluations of the offer (Mano \& Oliver, 1993), constituting an important determinant of attitude for hedonic products (Kempf, 1999). Conversely, functional goods embed a rational appeal and cognitively oriented benefits. Research argued that functional products generate less arousal (Hirschman, 1980; Woods, 1960) than hedonic ones and such arousal is not an important determinant of attitude (Kempf, 1999). However, recent research suggests that additional factors may influence the evaluation of products, raising doubts about the validity of the mere product nature as an explanation of the different emotional responses and evaluations. For instance, Hess et al. (2016) found that the nature of the decision task may influence the evaluation of hedonic and utilitarian goods while Lim \& Ang (2008) proved that feelings elicited by products may vary among cultures, where in cultures conditioned toward utilitarian consumption, utilitarian products are seen as more exciting. They argued that preference toward hedonic and functional products varies as well according to such cultural conditioning.

As for the product nature, also the trial context may moderate or even cause observable differences in emotional responses toward products. Consumers, indeed, may experience products through a direct experience, occurring from an unmediated interaction between the consumer and the product and involving full sensory capacities (Gibson, 1966), such as handson trial or inspection. They may conversely involve with goods through a virtual experience, by interacting with products in a computer-mediated environment, such as internet ( $\mathrm{Li}$, Daugherty, \& Biocca, 2001). The consumers' responses generated by both experiences have long been studied in research (Deighton, 1984; Hoch \& Ha, 1986; Kempf \& Smith, 1998). The 
direct hands-on experience has been acknowledged as more trustworthy for a consumer, as the consumer controls the focus and pace of the product inspection to maximise the information gathered (Li et al., 2001). Further, the direct trial may elicit higher involvement compared to a virtual trial, potentially generated by the availability of more processing resources (Sanbonmatsu \& Kardes, 1988) or the emotional involvement generated through product handling, as the mere ownership effect suggests (Beggan, 1992; Peck \& Shu, 2009). Researchers found the direct experience generates more affective responses in a consumer than the indirect experience (Millar \& Millar, 1996) and influences consumer judgments through affective responses (Olson \& Dover, 1979; Smith \& Swinyard, 1988). However, virtual interaction is accredited as a vivid, involving and active experience as well (Li et al., 2001), able to generate emotional psychological states in individuals and affecting brand attitudes and decision confidence ( $\mathrm{Li}$ et al., 2001). Internet, indeed, may create a sense of interactivity and enjoyment in consumers (Hoffman \& Novak, 1996; Huang, 2006). Researchers posit that a virtual experience may be perceived equivalent to a direct experience as it incorporates elements of the direct experience as well, such as providing to the user the freedom to inspect the product at his own pace plus additional information about the product (Daugherty, Li, \& Biocca, 2008). We formalise our hypotheses below:

H4: Product nature moderates the influence of arousal on attitude toward the product

H5: Trial context moderates the influence of arousal on attitude toward the product

\section{Methodology}

\subsection{Measurements}

To assess unconscious arousal we used physiological measures, specifically electrodermal activity (EDA), which assesses autonomic changes in the electrical properties of the skin. EDA, above measuring arousal in the instant in which the individual feels it, distinguishes among the baseline emotions, states or moods (the tonic level) and the emotions induced by the stimulus (the phasic level). Electrodermal activity has been recognised as a valid and sensitive indicator of arousal that may occur without awareness or is beyond cognitive intent (Braithwaite, Watson, Jones, \& Rowe, 2013). A broad consensus exists among researchers who have recognised changes in EDA as a reflection of changes in the level of activation generated during an emotional episode (Boucsein, 2012; Dawson, 2011; Dawson, Schell, \& Filion, 2007; Sequeira, Hot, Silvert, \& Delplanque, 2009). Such bodily activation that comes without awareness cannot 
be studied through self-reported scales that rely on individual awareness of the emotional reactions, measuring emotions through a cognitive assessment (Figner \& Murphy, 2011).

To measure conscious arousal and attitude we employed self-reported scales, broadly validated in prior research (e.g. Havlena \& Holbrook, 1986; Kempf, 1999). We measured conscious arousal with the scale developed by Mehrabian \& Russell (1974). The items used, listed in random order, were "excited-calm”, "stimulated-relaxed", "aroused-unaroused", "sluggishfrenzied", "dull-jittery" and "sleepy-wide awake". The items were introduced with this instruction (Bradley \& Lang, 1994) "Each line on the page contains an adjective pair which you will use to rate your feelings about the product. Some of the pairs may seem unusual, but you'll probably feel more one way about one side than another. So, for each pair, place a check mark close to the adjective which you believe describes your reaction to the picture better. The more appropriate the adjective seems, the closer you should put your check mark to it". Attitude was assessed through ten 7-points semantic differential items, listed in random order (enjoyable-unenjoyable, pleasant-unpleasant, comfortable-uncomfortable, attractiveunattractive, appealing-unappealing, rewarding-punishing, wise-foolish, beneficial-harmful, useful-useless, good-bad) (Bagozzi, Lee, \& Loo, 2001). The items were presented with this instruction: "For me personally, adopting this product in the next six months can be described as "(Bagozzi et al., 2001).

\subsection{Manipulations}

We performed two manipulations to rule out the potential effect of product nature (functional versus hedonic product) and trial context (direct versus virtual trial) on the variables of interest in our study, following prior research arguing these factors may moderate information processing and emotional responses of consumers. We believe that investigating the individual emotional and cognitive processes under different circumstances will provide robustness to our results.

\subsection{Pretest}

The major aim of the product pretest was to individuate two stimuli products that differ in terms of their hedonic or functional nature, but be similar in all other aspects that prior research suggests may affect product evaluation processing. To select two products that meet these criteria, a pretest was performed in which 20 subjects similar to those involved in the lab experiment answered questions about four personal electronic devices: a MP3 player, a smart body scale, a pedometer and a fitness tracker. The four products were selected by a team of 
researchers with the aim of including a variety of potential hedonic and utilitarian goods. Products were chosen thanks to their simplicity and ease of learning in a short time period, which was necessary to give subjects a meaningful product trial in a single experimental session. Further, their examination represents a realistic scenario for the subjects, being such products used by a large majority of the population under study. Finally, the brands chosen were unfamiliar in the market where the experiment was conducted. This is (i) to avoid extraexperimental sources of variance caused by brand-related feelings or attitudes (ii) to avoid attitude might be affected by the mere exposure to the product before the experiment ${ }^{1}$.

The test was performed by showing to respondents a representative image of the products together with a short description and ask them to rate each product on a 7-points scale according to the perceived functional versus hedonic characteristics. This approach is similar to the one adopted in prior studies (Kempf, 1999). Specifically, we asked: "Would you characterise the [product] as primarily a functional product or an entertainment/enjoyable product?" with a 7points scale, with 1 being "primarily for functional use" and 7 being "primarily for entertainment use" (Kempf, 1999). We conducted a paired t-test on each couple of products and chosen the two devices that differ more in terms of perceived functional versus hedonic characteristics: the MP3 player $(M=1.5 ; \mathrm{SD}=0.8)$ and the body diagnostic scale $(\mathrm{M}=5.33$; $\mathrm{SD}=1.4)$. The $\mathrm{t}$-test showed a significant difference $(t 18=10.16 ; p<0.001)$.

\subsection{Lab experiment}

One hundred sixty individuals participated in the experiment, conducted in the behavioural lab of a major U.S. University. The experiment employed a 2 x 2 between-subjects factorial design that manipulated (1) the trial context (direct trial versus virtual trial) (2) the product nature (functional versus hedonic). Randomly selected, 40 participants were assigned to the hedonic product direct trial (DM condition), 40 subjects to the functional product direct trial (DS condition), 40 participants to the hedonic product virtual trial (VM condition), and 40 subjects to the functional product virtual trial (VS condition). This sample size allowed thirteen observations for each independent variable per experiment cell, thus satisfying the minimum commonly accepted ratio of 5 to 1 (Hair, Anderson, Tatham, \& Black, 1995). Further, the sample size permitted a maximum likelihood estimation of the model.

\footnotetext{
${ }^{1}$ The mere exposure effect implies that when products are presented to a subject in repeated occasions, such exposure may induce a more positive attitude toward the products (Zajonc \& Markus, 1982).
} 
The procedure was identical across conditions: before the experiment, subjects were informed about the use of electrophysiological recording equipment and were told they could withdraw from the experiment at any time. Subjects were instructed that the aim of the study was to assess their evaluation of a product and that after the product examination they will be asked to complete a questionnaire to record their evaluation. This procedure, according to prior research (Kempf \& Smith, 1998) serves to prime the respondents to engage in product evaluation. All the subjects participated in the experimental task in its entirety and were paid in exchange for their participation. The lab experiment followed this process: subjects wore a skin conductance device and were asked to perform a light physical activity (walk up and down on the stairs) for five minutes to produce changes in the skin wet level that enable EDA activation. To reduce potential motion artefacts, we secured the EDA sensor on the wrist with sufficient tensioning so that the electrodes stay in contact with the skin in case the subject moves its hands or arm around. We also asked each participant to keep arm and hand movements at minimum during the experiment. Then, participants were escorted by a research assistant in the area of the computer lab corresponding to their randomly assigned condition and rested for 10 minutes. This procedure was necessary to assess a baseline for each respondent, a condition against which physiological changes during the experiment can be compared. During the rest period subjects answered to a questionnaire not related to the present study. To assure the absence of any kind of social influence, subjects had not the possibility to interact with other subjects during the experiment.

All subjects in the direct trial were given a short, self-directed, hands-on trial of one of the two products. Manual instruction on how to run the products were provided. Participants in the virtual trial browsed the product web page, designed ad hoc for each product. Ad hoc pages assure that (i) respondents do not browse other web pages or get distracted by web banners and pop-ups as it may happen while browsing real web pages (ii) we could design identical web pages for the two products under test, to avoid differences in the virtual experiences. Product web pages included a general as well as a detailed description of product features, the online manual and pictures of the product. They had the same layout, colours and interaction possibilities. In order to minimise underexposure or overexposure to one type of experience yet provide enough duration not to affect the inherent advantages associated with direct and virtual experiences, the exposure time for each condition was limited to five minutes, according to prior research (Daugherty et al., 2008). After the trial, subjects were invited to answer to a selfreported questionnaire. Electrodermal activity data were recorded during the whole experiment. 


\section{Results}

Following data detection, we deleted two questionnaires due to incomplete and unreliable answers, obtaining 158 complete answers. After checking for measure reliability, we deleted one item from the arousal scale (excited-calm) and one from the attitude scale (comfortableuncomfortable). Further analyses were conducted on this data set. Demographic statistics are shown in Appendix. Electrodermal data, recorded on Affectiva Q Sensor device were analysed with LEDALAB analysis software (www.ledalab.de), implemented in MATLAB. A visual check of EDA signals allowed the detection of possible artefacts. The cleaned signal (an example is shown in Figure 2) was analysed by the method of continuous decomposition analysis (CDA- Benedek \& Kaernbach, 2010). The EDA signal includes a tonic activity (slow) and phasic activities (fast), which need to be evaluated separately (Boucsein, 2012). The tonic activity gives the individual's subjective skin conductance level, which varies across individuals (Dawson et al., 2007). Phasic activities reflect the activation component of an emotional reaction, the skin conductance responses (SCR), elicited by a stimulus. LEDALAB software provides several quantification indices of SCR, such as ISCR (the integral skin conductance responses) and the sum of the amplitude peaks (Amp_Sum). Although most of the studies in consumer neuroscience and psychophysiology used the amplitude of SCR to quantify phasic activity, many researchers now agree that the area under the curve of the phasic activity (ISCR) could be a better indicator of emotional arousal (e.g. Benedek \& Kaernbach, 2010; Boucsein, 2012). ISCR calculation involves the integration of the SCRs over a specified response window, the one in which the stimulus and subsequent reaction occur (Benedek \& Kaernbach, 2010). Our response window was of 5 minutes, the time available to subjects to interact with the product.

[Figure 2 about here]

To reduce between-subjects differences in response magnitude, EDA data were standardised. Data normalisation was performed by applying the following formula (Venables \& Christie, 1980): $S C^{*} \_\log \left(1_{\_}|S C|\right)$. Then, before performing statistical analyses on electrodermal data, we checked normality and equality of variances assumption. We found data non-normally distributed, thus we proceed with a non-parametric Levene's test to assess the equality of variances in non-normally distributed data. We found a p-value above 0.05 confirming equality of variances, thus we proceed with following analyses. 


\subsection{Manipulation checks}

We first checked if our manipulations were successful, by asking subjects to report the perceived product nature, using the same approach adopted in the pretest. As expected, subjects perceived the body scale as a functional product, with a mean of $1.97(\mathrm{SD}=1.28)$ and the MP3 player as a hedonic product, with a mean of $5.58(\mathrm{SD}=1.73)$. These means were significantly different $(t(156)=-14.901, p<0.05)$, confirming the goodness of the manipulation. Regarding trial context, we measured the situational involvement at the end of the study through three 7points Likert scale, randomly listed, asking: "I was absorbed intensely in examining the product presentation", "I concentrated fully on viewing the product presentation" and "My attention was focused on examining the product" (Webster \& Ho, 1997). A t-test confirmed a difference $(t(156)=3.853 ; p<0.01)$ between conditions with a mean of $5.23(\mathrm{SD}=1.26)$ for the virtual trial and $5.90(\mathrm{SD}=0.9)$ for the direct trial.

\subsection{Confound checks}

We measured product perceived diagnosticity, the perceived ability of a trial to help in product understanding. This check is important in order to assure that no differences were perceived between the two products and between the virtual and direct trial, given that prior studies confirmed that diagnosticity might affect product experience processing (Hoch \& Ha, 1986; Kempf \& Smith, 1998). Moreover, it is possible that if some sources of brand information (such as traditional or online advertisement, websites showing the product) had been available to subjects before the experiment, they could have affected the product perceived diagnosticity as well. In our study subjects were not familiar with the brands, thus this risk was minimal. Product diagnosticity was assessed via a single-item scale by asking: "Overall, how helpful would you rate the direct [virtual] experience you just had in judging the quality and performance of the product?" Responses were assessed on a 1-7 scale with the end points labelled "not helpful at all" and "extremely helpful"(Kempf, 1999). The mean of perceived diagnosticity for the four conditions was $4.38(\mathrm{SD}=1.31)$ for VS, $4.21(\mathrm{SD}=1.54)$ for $\mathrm{VM}, 4.68(\mathrm{SD}=1.68)$ for $\mathrm{DS}$ and $4.7(\mathrm{SD}=1.71)$ for $\mathrm{DM}$. A one-way ANOVA was conducted across the four conditions. The result $(F(158)=1.17, p=0.323)$ indicated no differences among conditions.

To make sure subjects were not aware of the product brands, we measured brand awareness via two items on a 7-points Likert scale "I am aware of this brand" and "I can recognise this brand among other competing brands"(Yoo, Donthu, \& Lee, 2000). Brand awareness was very low for both the hedonic product $(\mathrm{M}=2.02 ; \mathrm{SD}=1.16)$ and the functional product $(\mathrm{M}=2.08$; 
$\mathrm{SD}=1.16$ ) suggesting that the two brands were new for the subjects, thus prior attitude toward the brand is likely not an issue.

\subsection{Conscious and unconscious arousal correlation}

Our first objective is to test if conscious and unconscious arousal are two distinct emotional responses. Thus, we measured the correlation, through a two-tailed Spearman's Rho, between subjective arousal (mean) and physiological one testing its three measures: Amp_Sum, SCR and ISCR. All correlations were not significant with a value of $\mathrm{r}=0.02, \mathrm{r}=0.005$ and $\mathrm{r}=0.005$ respectively, thus confirming our $\mathrm{H} 1$. Further, we tested if conscious and unconscious arousal differ between product trial contexts. To verify this, one should observe a change in the unconscious arousal value coupled with flat conscious arousal between direct and virtual trial. In such situation, we would have evidence of a dissociation between conscious and unconscious arousal. Hence, we proceed with a post hoc U Mann-Whitney test for the difference in unconscious arousal values between virtual and direct trial. Results show a $\mathrm{Z}=-2.611$ with a $\mathrm{p}$ value $<0.01$, demonstrating that unconscious arousal value in the direct trial is significantly higher than in the virtual one. We analysed conscious arousal value through a t-test and we found that, conversely, it was not significantly different between trials $(t(156)=-0.695 ; p=$ 0.488). Thus, direct trial context results in greater unconscious arousal but not in increased conscious arousal, further confirming the dissociation between the two responses.

\subsection{Conscious and unconscious arousal influence on attitude}

Our second aim was to analyse the influence of conscious and unconscious arousal on attitude. We used Partial Least Squares Structural Equation Modeling (PLS-SEM), a second-generation multivariate data analysis method that permits to test linear and additive models. We opted for PLS-SEM due to the limited sample size and the distribution-free nature of the method, being EDA data non-normal distributed (Hwang, Malhotra, Kim, Tomiuk, \& Hong, 2010). Constructs included in the analysis were: conscious arousal, unconscious arousal and attitude. We investigated the impact of unconscious arousal on conscious arousal and the impact of unconscious and conscious arousal on attitude. Our model was balanced in the weight of endogenous and exogenous constructs, meeting PLS-SEM prediction goals (Hair, Sarstedt, Ringle, \& Mena, 2012). All our constructs were reflective. 


\subsubsection{Measurement model}

We examined the reliability and validity of constructs with the pooled data (Haenlein \& Kaplan, 2004) through their outer loadings, composite reliability, AVE and AVE square root. Results are reported in Table 1 and Table 2.

[Table 1 about here]

[Table 2 about here]

We assessed internal consistency reliability of constructs through composite reliability, a more appropriate indicator than Cronbach's Alfa (Werts, Linn, \& Jöreskog, 1974). While Cronbach's Alfa assumes that all indicators are equally reliable, PLS prioritises indicators according to their reliability, resulting in a more reliable composite. Internal consistency reliability was higher than 0.83 for each construct thus satisfying the requirement of 0.7 as a minimum (Bagozzi \& Yi, 1988). Indicator reliability was assured through the mean of the squared outer loadings with an average of 0.8 and with the lowest indicator with a value of 0.67 . Convergent validity, measuring the latent construct ability to explain a great share of the variance of its indicators, was measured through AVE numbers. The lowest construct showed a value of 0.71 , higher than the suggested threshold of 0.5 (Bagozzi \& Yi, 1988). We assessed discriminant validity with two criteria: (i) Fornell \& Larcker (1981) criterion, which assesses discriminant validity on the construct level and imposes the "square root" of AVE to be greater than the correlations among the latent variables. All our AVE square roots were highly satisfying this condition; (ii) the loading of each indicator that is expected to be greater than all of its cross-loadings (Chin, 1998), evaluating discriminant validity on the indicator level. We satisfied this criterion as well.

\subsubsection{Structural model}

To assess potential differences in the arousal reaction generated by the product trial experience (virtual versus direct) we performed two path analyses, one for each condition. We split the data into two sets, direct and virtual trial, for PLS multigroup comparisons (Sarstedt, Henseler, \& Ringle, 2011), obtaining two groups of 79 observations each. Our sample size was satisfactory, being more than ten times the largest number of structural paths directed to a particular latent construct in the structural model (Barclay, Higgins, \& Thompson, 1995). For each group, we run 5000 bootstrap samples as suggested by Hair, Ringle, \& Sarstedt (2011) and we used 'no sign changes' criteria, the most conservative one. The number of iterations to find convergence were respectively 4 and 6 , suggesting the goodness of the model. 
Furthermore, we analysed the potential moderation effect of product nature (functional versus hedonic). Results are shown in Table 3.

[Table 3 about here]

Results show that unconscious arousal is not a predictor of conscious arousal in both conditions. The structural model results show that conscious arousal has a positive effect on attitude for both direct and virtual trials, confirming H2. Unconscious arousal has a negative impact on attitude on direct trial, but not on virtual one, partially confirming H3. Effect sizes are large to medium according to Cohen $(1988)^{2}$. Model's predictive relevance is assessed through StoneGeisser's $Q^{2}$ (Stone, 1974; Geisser, 1974), using blindfolding procedures (Tenenhaus \& Vinzi, 2005). $q^{2}$ values, measured through construct cross validated redundancy, confirm the predictive relevance of the constructs. A group comparison between virtual and direct trials has been performed, to check if the structural relationships were statistically different. Results show the influence of unconscious arousal on attitude is significantly higher in direct trial than in virtual trial $(t=2.025 ; p<0.05)$ while the influence of conscious arousal on attitude is not statistically different between the trials. Overall, the share of attitude explained in direct trial is higher than in virtual trial. Both are moderate values that according to Chin (1998) are appropriate for our typology of research ${ }^{3}$. These findings confirm that the trial context moderates the relationship between unconscious arousal and attitude, but not between conscious arousal and attitude, partially confirming our H5. Results show that product nature (functional versus hedonic) is not a moderator in both contexts, not supporting our H4.

\section{Discussion}

Our findings show that when a consumer is exposed to a product stimulus two emotional responses arise, namely conscious arousal and unconscious arousal and they are disassociated from one another. This result has several implications for research in marketing that predominantly focuses on conscious arousal, measured through self-reported scales. Unconscious arousal has shown to be affected by the degree of context involvement, being greater in high involving situations such as the hands-on trial of a product and lower for less involving contexts, as during virtual interaction with the product. Conversely, conscious arousal does not show a significant difference between trial contexts, confirming again the

\footnotetext{
${ }^{2}$ According to Cohen (1988), $f^{2}$ values of $0.02,0.15$ and 0.35 signify small, medium and large effects, respectively.

${ }^{3}$ Chin (1998) describes $R^{2}$ values of 0.67, 0.33 and 0.19 in PLS path models as substantial, moderate, and weak respectively, with a moderate value that is acceptable for explorative models or if the endogenous construct has only a few predictors.
} 
independence of the two responses. We speculate that such higher involvement generated by the direct trial compared to the virtual experience may be elicited by the emotional involvement generated through product handling, as the mere ownership effect suggests (Beggan, 1992; Peck \& Shu, 2009).

Our results indicate that in the direct trial, where unconscious arousal shows to be greater, the proportion of attitude variability we are able to explain increases. This can be the consequence of the availability of greater resources (compared to virtual trial), that lead consumers to form a more accurate attitude toward the product (Malhotra, 2005). When individuals feel a high level of arousal, indeed, they experience a reduction of the processing capacity available for cognitive evaluations and they tend to use peripheral cues to form attitude (Sanbonmatsu \& Kardes, 1988). We did not find any significant distinctive role of arousal and attitude across the different product types (functional and hedonic). Thus, we did not confirm prior studies arguing that hedonic products should induce higher arousal (e.g. Kempf, 1999; Mano \& Oliver, 1993). Overall, we predicted more than $40 \%$ of the variance in attitude, for both direct and virtual trials, functional and hedonic products, confirming the importance of arousal in product evaluation. Conscious arousal shows to be a strong positive predictor of attitude for both direct and virtual trials. Unconscious arousal negatively affects attitude only in the direct trial. It is important to notice that, in this scenario, the negative effect of unconscious arousal and the positive effect of conscious arousal on attitude confirm again the disassociation between the two emotional responses.

\section{Implications for research}

Understanding how consumers process product experience is an important issue to marketing researchers. Our work has four important implications: (i) we extend prior literature (Allen et al., 2005; Bagozzi, et al., 1999; Berridge \& Winkielman, 2003; Lerner et al., 2015; Smith \& Lane, 2016) by conceptually clarifying the nature of the relationship between conscious arousal and unconscious arousal and their influence on attitude (ii) we empirically proved that conscious arousal, measured through self-reported scales and unconscious arousal, assessed through physiological parameters, are two disassociated emotional responses. This suggests that self-reported arousal measures, the traditional method use in marketing research (Bradley \& Lang, 1994; Mehrabian \& Russell, 1974), are not sufficient to explain the overall emotional response of individuals. (iii) $\mathrm{We}$ found that conscious and unconscious arousal have a significant and divergent effect on attitude. This reinforces the distinct nature of the two 
emotional responses and suggests that both conscious and unconscious arousal should be considered in attitude formation research. Used in concert, self-reported and physiological assessment can provide a more detailed and accurate representation of the consumer's emotional experience and its impact on attitude toward the product. (iv) Finally, we advanced research in product experience by showing that arousal (1) varies between direct trials and virtual trials, confirming prior research (Beggan, 1992; Peck \& Shu, 2009; Sanbonmatsu \& Kardes, 1988); (2) does not vary between functional products and hedonic products, diverging from prior studies (Batra \& Ahtola, 1991; Kempf, 1999).

\section{Managerial implications}

Understanding the different emotional reactions generated by products and how they affect the evaluation of the offer is relevant for marketers that need insights on how to promote their products. The use of physiological observations to capture unconscious arousal elicited by product trial enables a deeper understanding of the consumer's experience. Complementary self-reported measures enrich such understanding and provide access to both the conscious and subconscious experiences of the consumer. Managers can use this information to effectively promote their brands, by providing the desirable advertising stimuli, both in online and traditional contexts, for the specific product they are marketing.

This research suggests that functional product evaluation, traditionally regarded as predominantly cognitive oriented, is influenced by affective responses in the same extent as hedonic product evaluation. Thus, marketers should carefully understand the emotional experience their offer generates, that does not depend on the typology of product they are selling. Even functional products, conceived for utilitarian purposes, can elicit emotional responses in consumers. Such an understanding can help marketers in addressing product communication accordingly, in a way that intrigues consumers and elicits positive emotions, able to drive purchase intention. If managers want to provide extraordinary consumer experience, indeed, they need to understand how the consumer feels. Further, the responses generated by different trial contexts must be understood, as emotional responses vary between hands-on trial and virtual interaction. In this extent, marketers need to devote a specific attention to hands-on trials, in which the emotional aspect is highly influential and may generate negative emotions in consumers. They should manage affective responses to websites and online touch points with the consumers as well, as they are akin to generate arousal. Understanding these patterns, above helping managers in shaping marketing mix strategies, can also guide designers 
in controlling the emotional responses to their product designs. For instance, designers may assess which specific attributes of products stimulate arousal in individuals and design products accordingly to the emotional experience they want to provide. They may design exciting or relaxing experiences according to the image and meaning the product would convey and the specific target to which it is addressed.

\section{Limitations and future research}

This study, of course, has a number of limitations that suggest immediate further developments. Firstly, the choice of the laboratory experiment as empirical setting provides higher internal validity being not affected by external influences but is lower in external validity. The artificiality of the setting may have produced unnatural behaviours in consumers that do not reflect real life behaviours. Thus, it limits generalizability to real environments in which consumers actually try products. Secondly, despite the negative effect of unconscious arousal on attitude has been claimed also by prior studies, future research should analyse which are the factors eliciting this reaction in consumers. Knowing them may help marketers to reduce their potential negative impact on attitude a priori and thus enhance a positive evaluation of the product. Thirdly, we measured unconscious arousal through electrodermal activity and conscious arousal through self-reported scales, revealing that both measures are necessary. However, other methods can reveal additional insights on emotional responses. Thus, it would be interesting if future studies investigate arousal through different instruments, such as emotional face detection or heart rate.

\section{References}

Allen, C., Machleit, K., Kleine, S., \& Notani, A. (2005). A place for emotion in attitude models. Journal of Business Research, 58(4), 494 - 499.

Bagozzi, R. P. (1996). The role of arousal in the creation and control of the halo effect in attitude models. Psychology \& Marketing, 13(3), 235-264.

Bagozzi, R. P., Lee, K., \& Loo, M. Van. (2001). Decisions to donate bone marrow: The role of attitudes and subjective norms across cultures. Psychology and Health, 16(1), 29-56.

Bagozzi, R. P., \& Yi, Y. (1988). On the evaluation of structural equation models. Journal of the Academy of Marketing Science, 16(1), 74-94.

Bagozzi, R. P., Gopinath, M., \& Nyer, P. U. (1999). The Role of Emotions in Marketing. Journal of the Academy of Marketing Science, 27(2), 184-206. 
Baker, J., Levy, M., \& Grewal, D. (1992). An experimental approach to making retail store environmental decisions. Journal of Retailing, 68(4), 445.

Barclay, D., Higgins, C., \& Thompson, R. (1995). The Partial Least Squares (PLS) Approach to Causal Modelling: Personal Computer Adoption and Use as an Illustration. Technology Studies, 2(2), 285-309.

Batra, R., \& Ahtola, O. (1991). Measuring the hedonic and utilitarian sources of consumer attitudes. Marketing Letters, 2(2), 159-170.

Bauer, R. (1998). Physiologic measures of emotion. Journal of Clinical Neurophysiology, 15(5), 388-396.

Beggan, J. K. (1992). On the social nature of nonsocial perception: The mere ownership effect. Journal of Personality and Social Psychology, 62(2), 229-237.

Benedek, M., \& Kaernbach, C. (2010). Decomposition of skin conductance data by means of nonnegative deconvolution. Psychophysiology, 47(4), 647-658.

Bentler, P., \& Speckart, G. (1979). Models of attitude-behavior relations. Psychological Review, 86(5), 452.

Berridge, K., \& Winkielman, P. (2003). What is an unconscious emotion?(The case for unconscious "liking"). Cognition \& Emotion, 17(2), 181-211.

Boucsein, W. (2012). Electrodermal activity (Second.). Springer Science \& Business Media.

Bradley, M., \& Lang, P. (1994). Measuring emotion: the self-assessment manikin and the semantic differential. Journal of Behavior Therapy and Experimental Psychiatry, 25(1), 49-59.

Braithwaite, J., Watson, D., Jones, R., \& Rowe, M. (2013). A guide for analysing electrodermal activity (EDA) \& skin conductance responses (SCRs) for psychological experiments. Psychophysiology, 49, 1017-1034.

Brenner, C. (1973). The Psychic Apparatus. In An Elementary Textbook of Psychoanalysis. International Universities Press.

Cacioppo, J., \& Berntson, G. (2000). The psychophysiology of emotion. Handbook of Emotions, 2, 173-191.

Chin, W. (1998). The partial least squares approach to structural equation modeling. Modern Methods for Business Research, 295(2), 295-336.

Chitturi, R., Raghunathan, R., \& Mahajan, V. (2008). Delight by design: The role of hedonic versus utilitarian benefits. Journal of Marketing, 72(2), 48-63.

Cohen, J. (1988). Statistical power analysis for the behavioral sciences. Hillsdale, New Jersey: Lawrence Erlbaum Associates. 
Daugherty, T., Li, H., \& Biocca, F. (2008). Consumer learning and the effects of virtual experience relative to indirect and direct product experience. Psychology \& Marketing, 25(7), 568-586.

Dawson, M. (2011). The skin conductance response, anticipation, and decision-making. Journal of Neuroscience, Psychology, and Economics, 4(2), 111-116.

Dawson, M., Schell, A., \& Filion, D. (2007). The Electrodermal System. In Handbook of psychophysiology (p. 159). Cambridge University Press.

Dehaene, S., Changeux, J. P., \& Naccache, L. (2011). The global neuronal workspace model of conscious access: From neuronal architectures to clinical applications. Research and Perspectives in Neurosciences, 18, 55-84.

Deighton, J. (1984). The Interaction of Advertising and Evidence. Journal of Consumer Research, 11(3), 763-770.

Drachen, A., \& Nacke, L. (2010). Correlation between heart rate, electrodermal activity and player experience in first-person shooter games. In Proceedings of the 5th ACM SIGGRAPH Symposium on Video Games (pp. 49-54).

Figner, B., \& Murphy, R. (2011). Using skin conductance in judgment and decision making research. In A handbook of process tracing methods for decision research (pp. 163-184).

Fishbein, M., \& Ajzen, I. (1975). Belief, attitude, intention, and behavior: an introduction to theory and research. Addison-Wesley Publishing Company.

Fornell, C., \& Larcker, D. (1981). Evaluating structural equation models with unobservable variables and measurement error. Journal of Marketing Research, 18(1), 39-50.

Gardner, M. (1985). Mood States and Consumer Behaviour: A critical review. Journal of Consumer Research, 12(3), 281-300.

Gavazzeni, J., Wiens, S., \& Fischer, H. (2008). Age effects to negative arousal differ for selfreport and electrodermal activity. Psychophysiology, 45(1), 148-151.

Geisser, S. (1974). A predictive approach to the random effect model. Biometrika, 61(1), 101-107.

Gibson, J. (1966). The senses considered as perceptual systems. Oxford, England: Houghton Mifflin.

Groeppel-Klein, A. (2005). Arousal and consumer in-store behavior. Brain Research Bulletin, $67(5), 428-437$.

Haenlein, M., \& Kaplan, A. (2004). A beginner's guide to partial least squares analysis. Understanding Statistics, 3(4), 283-297.

Hair, J., Anderson, R., Tatham, R., \& Black, W. (1995). Multivariate data analysis (4th ed.). Upper Saddle River, NJ: Prentice Hall. 
Hair, J., Ringle, C., \& Sarstedt, M. (2011). PLS-SEM: Indeed a silver bullet. Journal of Marketing Theory and Practice, 19(2), 139-152.

Hair, J., Sarstedt, M., Ringle, C., \& Mena, J. (2012). An assessment of the use of partial least squares structural equation modeling in marketing research. Journal of the Academy of Marketing Science, 40(3), 413-433.

Havlena, W., \& Holbrook, M. (1986). The varieties of consumption experience: comparing two typologies of emotion in consumer behavior. Journal of Consumer Research, 13(3), 394-404.

Hess, N. C. L., Carlson, D. J., Inder, J. D., Jesulola, E., Mcfarlane, J. R., \& Smart, N. A. (2016). Clinically meaningful blood pressure reductions with low intensity isometric handgrip exercise. A randomized trial. Physiological Research, 65(3), 461-468.

Hill, R., \& Gardner, M. (1987). The Buying Process: Effects of and on Consumer Mood States. In Advances in Consumer Research (Vol. 14, pp. 408-410). Association for Consumer Research.

Hirschman, E. (1980). Attributes of attributes and layers of meaning. In Advances in Consumer Research (Vol. 7, pp. 7-12). Association for Consumer Research.

Hirschman, E., \& Holbrook, M. (1982). The Experiential Aspects of Consumption: Consumer Fantasies, Feelings, and Fun. Journal of Consumer Research, 9(2), 132-140.

Hoch, S., \& Ha, Y. (1986). Consumer learning: Advertising and the ambiguity of product experience. Journal of Consumer Research, 13(2), 221-233.

Hodgson, R., \& Rachman, S. (1974). II. Desynchrony in measures of fear. Behaviour Research and Therapy, 12(4), 319-326.

Hoffman, D. L., \& Novak, T. P. (1996). Marketing in Hypermedia Environment Foundations: Conceptual Foundations. Journal of Marketing, 60(3), 50-68.

Huang, Y.-R. (2006). Identity and intimacy crises and their relationship to internet dependence among college students. Cyberpsychology \& Behavior: The Impact of the Internet, Multimedia and Virtual Reality on Behavior and Society, 9(5), 571-576.

Hwang, H., Malhotra, N., Kim, Y., Tomiuk, M. A., \& Hong, S. (2010). A comparative study on parameter recovery of three approaches to structural equation modeling. Journal of Marketing Research, 47(4), 699-712.

Isen, A., Daubman, K., \& Nowicki, G. (1987). Positive affect facilitates creative problem solving. Journal of Personality and Social Psychology, 52(6), 1112-1131.

Ivonin, L., Chang, H. M., Chen, W., \& Rauterberg, M. (2013). Unconscious emotions: Quantifying and logging something we are not aware of. Personal and Ubiquitous Computing, 17(4), 663-673.

James, W. (1884). What is an emotion? Mind, 34, 188-205. 
Kempf, D. (1999). Attitude formation from product trial: Distinct roles of cognition and affect for hedonic and functional products. Psychology \& Marketing, 16(1), 35-50.

Kempf, D., \& Smith, R. (1998). Consumer processing of product trial and the influence of prior advertising: A structural modeling approach. Journal of Marketing Research, $35(3), 325-338$.

Kihlstrom, J. F. (1990). The psychological unconscious. In Handbook of personality. Theory and research (pp. 424-442). Guilford Press.

Kihlstrom, J. F. (1992). Dissociation and dissociations: A comment on consciousness and cognition. Consciousness and Cognition, 1(1), 47-53.

Kihlstrom, J. F., Mulvaney, S., Tobias, B. A., \& Tobis, I. P. (2000). The emotional unconscious. In Cognition and emotion. (pp. 30-86). Oxford University Press.

Kim, J., \& Morris, J. (2007). The power of affective response and cognitive structure in product-trial attitude formation. Journal of Advertising, 36(1), 95-106.

Kimura, Y., Yoshino, A., Takahashi, Y., \& Nomura, S. (2004). Interhemispheric difference in emotional response without awareness. Physiology and Behavior, 82(4), 727-731.

Lane, R., Nadel, L., Allen, J., \& Kaszniak, A. (2000). The Study of Emotion from the Perspective of Cognitive Neuroscience. In Cognitive Neuroscience of Emotion (pp. 311). Oxford University Press.

Lane, R., Quinlan, D., Schwartz, G. E., Walker, P. A., \& Zeitlin, S. B. (1990). The Levels of Emotional Awareness Scale: A cognitive-developmental measure of emotion. Journal of Personality Assessment, 55(1-2), 124-134.

Lazarus, R. (1991). Cognition and motivation in emotion. American Psychologist, 46(4), 352367.

Lee, N., Broderick, A., \& Chamberlain, L. (2007). What is "neuromarketing"? A discussion and agenda for future research. International Journal of Psychophysiology, 63(2), 199204.

Lerner, J., Li, Y., Valdesolo, P., \& Kassam, K. (2015). Emotion and decision making. Annual Review of Psychology, 66, 799-823.

Li, H., Daugherty, T., \& Biocca, F. (2001). Characteristics of virtual experience in electronic commerce: A protocol analysis. Journal of Interactive Marketing, 15(3), 13-30.

Lim, E. A. C., \& Ang, S. H. (2008). Hedonic vs. utilitarian consumption: A cross-cultural perspective based on cultural conditioning. Journal of Business Research, 61(3), 225232.

Malhotra, N. (2005). Attitude and affect: new frontiers of research in the 21st century. Journal of Business Research, 58(4), 477-482. 
Mano, H., \& Oliver, R. (1993). Assessing the dimensionality and structure of the consumption experience: Evaluation, feeling, and satisfaction. Journal of Consumer Research, 20(3), 451-466.

Mehrabian, A., \& Russell, J. (1974). An approach to environmental psychology. Cambridge, MA: The MIT press.

Millar, M. G., \& Millar, K. U. (1996). The Effects of Direct and Indirect Experience on Affective and Cognitive Responses and the Attitude-Behavior Relation. Journal of Experimental Social Psychology, 32(6), 561-579.

Modell, A. (2010). The unconscious as a knowledge processing center. In Knowing, notknowing and sort-of-knowing: psychoanalysis and the experience of uncertainty (pp. 45$61)$.

Oatley, K. (1992). Best laid schemes: The psychology of the emotions. Cambridge University Press.

Olson, J. C., \& Dover, P. a. (1979). Disconfirmation of consumer expectations through product trial. Journal of Applied Psychology, 64(2), 179-189.

Peck, J., \& Shu, S. B. (2009). The Effect of Mere Touch on Perceived Ownership. Journal of Consumer Research, 36(3), 434-447.

Rachman, S., \& Hodgson, R. (1974). I. Synchrony and desynchrony in fear and avoidance. Behaviour Research and Therapy, 12(4), 311-318.

Sanbonmatsu, D., \& Kardes, F. (1988). The effects of physiological arousal on information processing and persuasion. Journal of Consumer Research, 15(3), 379-385.

Sarstedt, M., Henseler, J., \& Ringle, C. (2011). Multigroup analysis in partial least squares (PLS) path modeling: Alternative methods and empirical results. Advances in International Marketing, 22(1), 195-218.

Sato, W., \& Aoki, S. (2006). Right hemispheric dominance in processing of unconscious negative emotion. Brain and Cognition, 62(3), 261-266.

Schachter, S., \& Singer, J. (1962). Cognitive, social, and physiological determinants of emotional state. Psychological Review, 69(5), 379-399.

Sequeira, H., Hot, P., Silvert, L., \& Delplanque, S. (2009). Electrical autonomic correlates of emotion. International Journal of Psychophysiology, 71(1), 50-56.

Sergent, C., \& Dehaene, S. (2004). Neural processes underlying conscious perception: Experimental findings and a global neuronal workspace framework. Journal of Physiology-Paris, 98(4), 374-384.

Smith, R., \& Lane, R. D. (2016). Unconscious emotion: A cognitive neuroscientific perspective. Neuroscience and Biobehavioral Reviews, 69, 216-238. 
Smith, R., \& Swinyard, W. (1988). Cognitive response to advertising and trial: Belief strength, belief confidence and product curiosity. Journal of Advertising, 17(3), 3-14.

Stone, M. (1974). Cross-validatory choice and assessment of statistical predictions. Journal of the Royal Statistical Society. Series B (Methodological), 36(2), 111-147.

Strahilevitz, M., \& Myers, J. (1998). Donations to charity as purchase incentives: How well they work may depend on what you are trying to sell. Journal of Consumer Research, 24(4), 434-446.

Tenenhaus, M., \& Vinzi, V. (2005). PLS path modeling. Computational Statistics \& Analysis, 48(1), 159-205.

Vaughan, G., \& Hogg, M. (2005). Introduction to social psychology. Pearson Education Australia.

Venables, P., \& Christie, M. (1980). Electrodermal activity. Techniques in Psychophysiology, 74(8), 3-67.

Ward, J., \& Barnes, J. (2001). Control and affect: the influence of feeling in control of the retail environment on affect, involvement, attitude, and behavior. Journal of Business Research, 54(2), 139-144.

Webster, J., \& Ho, H. (1997). Audience engagement in multimedia presentations. ACM SIGMIS Database, 28(2), 63-77.

Wertenbroch, K., \& Dhar, R. (2000). Consumer Choice Between Hedonic and Utilitarian Goods. Journal of Marketing Research, 37(1), 60-71.

Werts, C., Linn, R., \& Jöreskog, K. (1974). Intraclass reliability estimates: Testing structural assumptions. Educational and Psychological Measurement, 34(1), 25-33.

Wiens, S. (2005). Interoception in emotional experience. Current Opinion in Neurology, $18(4), 442-447$.

Winkielman, Piotr, \& Berridge, K. (2005). Emotion, behavior, and conscious experience. Emotion and Consciousness, 334-362.

Woods, W. (1960). Psychological dimensions of consumer decision. Journal of Marketing, 24(3), 15-19.

Yoo, B., Donthu, N., \& Lee, S. (2000). An examination of selected marketing mix elements and brand equity. Journal of the Academy of Marketing Science, 28(2), 195-211.

Zaidel, D., Hugdahl, K., \& Johnsen, B. (1995). Physiological responses to verbally inaccessible pictorial information in the left and right hemispheres. Neuropsychology, $9(1), 52-57$.

Zajonc, R., \& Markus, H. (1982). Affective and cognitive factors in preferences. Journal of Consumer Research, 9(2), 123-131. 
Zaltman, G. (1997). Rethinking market research: Putting people back in. Journal of Marketing Research, 34(4), 424-437.

Figure 1. Conceptual model

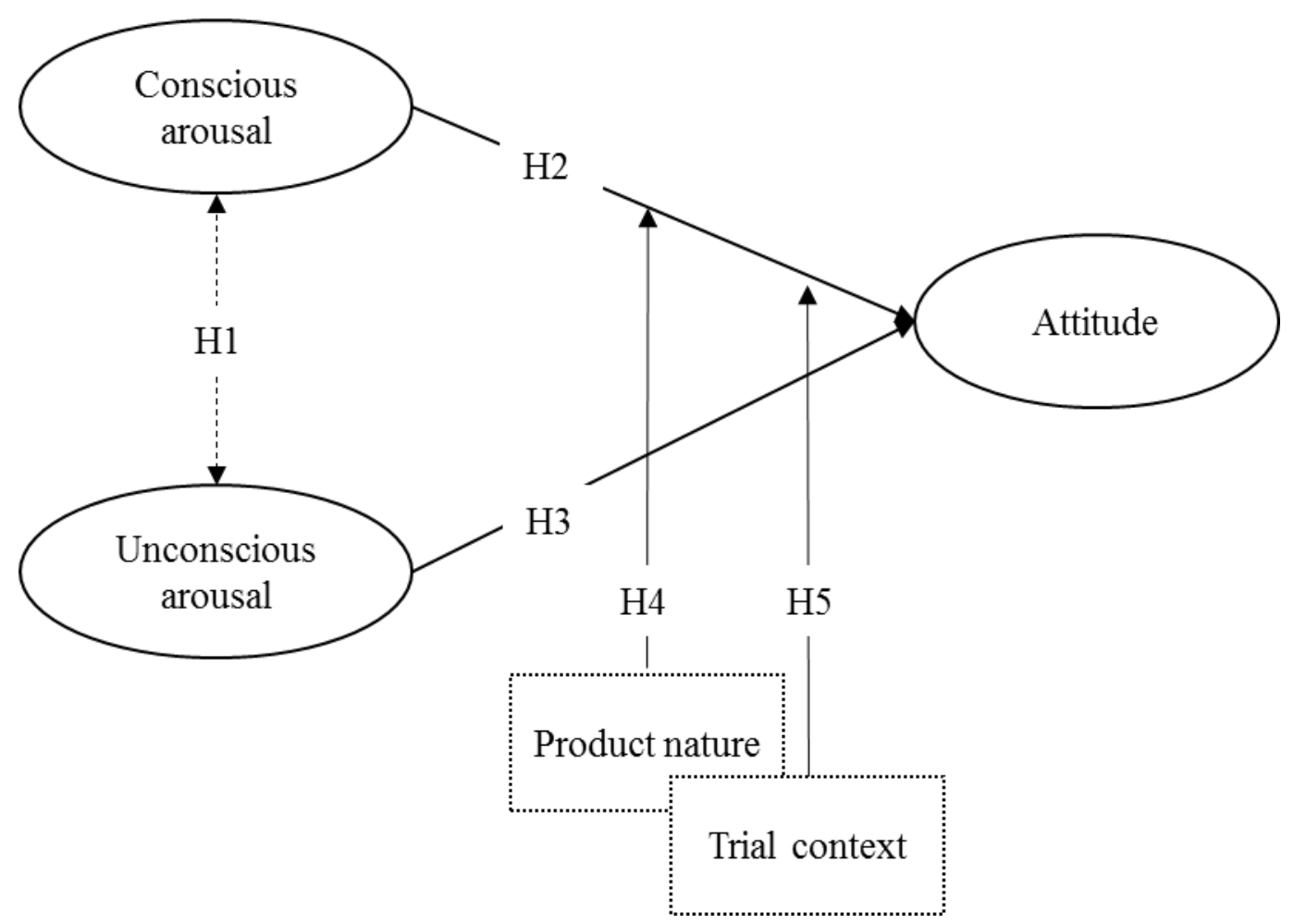

Figure 2. Example of electrodermal activity signal

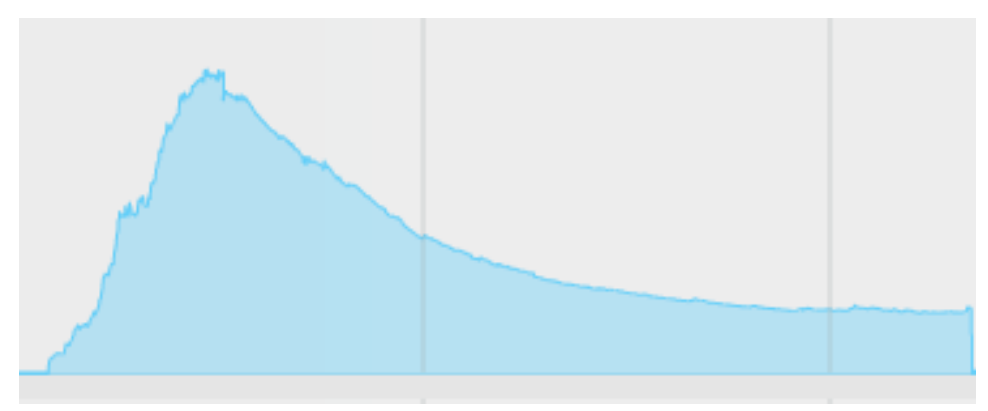

Table 1. Measurement model results ${ }^{\mathrm{a}}$

\begin{tabular}{|c|c|c|c|c|c|c|}
\hline \multicolumn{4}{|c|}{ Indicators loadings and reliability } & \multicolumn{3}{|c|}{ Outer model loadings and cross-loadings } \\
\hline Construct & Indicator & Loadings & $\begin{array}{l}\text { Indicator } \\
\text { reliability }\end{array}$ & UA & CA & Att \\
\hline \multirow{3}{*}{$\begin{array}{l}\text { Unconscious } \\
\text { arousal (UA) }\end{array}$} & CDA.AmpSum & 0.99 & 0.98 & 0.989 & 0.0121 & -0.1091 \\
\hline & CDA.ISCR & 0.98 & 0.95 & 0.9762 & 0.0101 & -0.0767 \\
\hline & CDA.SCR & 0.96 & 0.91 & 0.9564 & 0.0116 & -0.078 \\
\hline \multirow{2}{*}{$\begin{array}{l}\text { Conscious } \\
\text { arousal (CA) }\end{array}$} & CA1 & 0.83 & 0.68 & 0.0262 & 0.827 & 0.431 \\
\hline & CA2 & 0.88 & 0.78 & 0.0355 & 0.8839 & 0.5399 \\
\hline
\end{tabular}




\begin{tabular}{llllllr}
\hline & CA3 & 0.83 & 0.69 & -0.0011 & $\mathbf{0 . 8 3}$ & 0.6122 \\
& CA4 & 0.83 & 0.69 & -0.021 & $\mathbf{0 . 8 2 7 7}$ & 0.4626 \\
\hline Attitude (Att) & Att1 & 0.92 & 0.85 & -0.1147 & 0.5806 & $\mathbf{0 . 9 2 0 9}$ \\
& Att2 & 0.88 & 0.78 & -0.1275 & 0.5487 & $\mathbf{0 . 8 8 0 4}$ \\
& Att3 & 0.90 & 0.81 & -0.1104 & 0.5244 & $\mathbf{0 . 8 9 8 2}$ \\
& Att4 & 0.88 & 0.78 & 0.0009 & 0.5651 & $\mathbf{0 . 8 8 0 8}$ \\
& Att5 & 0.93 & 0.86 & -0.0897 & 0.6121 & $\mathbf{0 . 9 2 5 6}$ \\
& Att6 & 0.84 & 0.70 & -0.119 & 0.5152 & $\mathbf{0 . 8 3 6 3}$ \\
& Att7 & 0.87 & 0.76 & -0.0574 & 0.5092 & $\mathbf{0 . 8 6 9 1}$ \\
& Att8 & 0.85 & 0.73 & -0.0724 & 0.5218 & $\mathbf{0 . 8 5 1 9}$ \\
& Att9 & 0.89 & 0.80 & -0.0437 & 0.5299 & $\mathbf{0 . 8 9 1 8}$ \\
\hline
\end{tabular}

${ }^{a} \mathbf{N}=158$

Table 2. Inter construct correlation and reliability measures ${ }^{a}$

\begin{tabular}{|c|c|c|c|c|c|}
\hline Composite reliability & $\begin{array}{l}\text { Average Variance } \\
\text { Extracted (AVE) }\end{array}$ & Constructs & Att & CA & UA \\
\hline 0.97 & 0.78 & Att & $\mathbf{0 . 8 8}^{\mathrm{b}}$ & & \\
\hline 0.91 & 0.71 & $\mathrm{CA}$ & 0.62 & 0.84 & \\
\hline 0.98 & 0.95 & UA & -0.09 & 0.01 & 0.97 \\
\hline $\begin{array}{l}\text { a } \mathrm{N}=158 \\
\text { bSquared correlations }\end{array}$ & ng constructs & & & & \\
\hline
\end{tabular}

Table 3. Results summary for structural model ${ }^{a b}$

\begin{tabular}{|c|c|c|c|c|c|c|c|c|c|}
\hline & & \multicolumn{4}{|c|}{ Direct trial } & \multicolumn{4}{|c|}{ Virtual trial } \\
\hline & & \multicolumn{3}{|c|}{ Main effect } & Total effect & \multicolumn{3}{|c|}{ Main effect } & Total effect \\
\hline & $\begin{array}{l}\text { Path } \\
\text { coeff }\end{array}$ & $S E$ & $f^{2}$ & $q^{2}$ & $\begin{array}{l}\text { Path } \\
\text { coeff }\end{array} \quad$ SE & $\begin{array}{l}\text { Path } \\
\text { coeff }\end{array}$ & $S E$ & $f^{2}$ & $\begin{array}{l}\text { Path } \\
\text { coeff }\end{array}$ \\
\hline$U A-->C A$ & -0.04 & 0.11 & & & & 0.09 & 0.11 & & \\
\hline$C A-->A t t$ & $0.51^{* * *}$ & 0.10 & 0.41 & 0.31 & & $0.65^{* * *}$ & 0.08 & $\begin{array}{ll}0.56 & 0.31\end{array}$ & \\
\hline$U A-->A t t$ & $-0.21 *$ & 0.08 & 0.08 & 0.06 & $-0.23 * \quad 0.10$ & 0.05 & 0.10 & & 0.11 \\
\hline $\begin{array}{l}U A^{*} P d t \\
\rightarrow A t t\end{array}$ & 0.08 & 0.11 & & & & -0.15 & 0.19 & & \\
\hline \multirow[t]{2}{*}{$\begin{array}{l}U A * P d t \\
->A t t\end{array}$} & -0.00 & 0.09 & & & & 0.02 & 0.10 & & \\
\hline & $R^{2}$ & $Q^{2}$ & & & & $R^{2}$ & $Q^{2}$ & & \\
\hline Attitude & $48 \%$ & $39.1 \%$ & & & & $40.8 \%$ & $30.4 \%$ & & \\
\hline$N=79 a$ & & & & & & $N=79^{b}$ & & & \\
\hline
\end{tabular}


Appendix. Demographic statistics ${ }^{a}$

\begin{tabular}{|c|c|c|c|}
\hline \multicolumn{2}{|l|}{ Gender } & \multicolumn{2}{|l|}{ Field of Education } \\
\hline Male & $33.5 \%$ & $\begin{array}{l}\text { Education, Arts, Social } \\
\text { science, Humanities }\end{array}$ & $23.4 \%$ \\
\hline Female & $66.5 \%$ & Business, Law & $27.6 \%$ \\
\hline Age & & $\begin{array}{l}\text { Biological, Agriculture, } \\
\text { Medical }\end{array}$ & $28.8 \%$ \\
\hline $18-25$ & $79.1 \%$ & Science, Engineering & $15.2 \%$ \\
\hline $26-34$ & $7.6 \%$ & Missing & $7 \%$ \\
\hline $35-54$ & $8.9 \%$ & Nationality & \\
\hline 55 or over & $1.9 \%$ & Canada & $1.3 \%$ \\
\hline Missing & $2.5 \%$ & China & $4.4 \%$ \\
\hline Education & & South America & $0.6 \%$ \\
\hline High School & $10.1 \%$ & Africa & $1.9 \%$ \\
\hline Some College & $48.7 \%$ & Europe & $3.8 \%$ \\
\hline 2-year College D. & $2.5 \%$ & South East Asia & $5.1 \%$ \\
\hline 4-year College D. & $25.9 \%$ & South Asia & $5.1 \%$ \\
\hline Masters Degree & $10.8 \%$ & Japan \& South Korea & $3.8 \%$ \\
\hline Doctoral Degree & $0.6 \%$ & USA & $72.2 \%$ \\
\hline $\begin{array}{l}\text { Professional } \\
\text { Degree (JD, MD) }\end{array}$ & $1.3 \%$ & Missing & $1.9 \%$ \\
\hline $\mathrm{N}=158^{\mathrm{a}}$ & & & \\
\hline
\end{tabular}

This is an accepted manuscript of an article published in Journal of Business Research, available online at: http://dx.doi.org/10.1016/j.jbusres.2017.02.008 